\title{
OLDER PEOPLE AND SMARTWATCHES, INITIAL EXPERIENCES
}

\section{Adultos mayores y smartwatches, primeras experiencias}

Andrea Rosales, Mireia Fernández-Ardèvol, Francesca Comunello, Simone Mulargia and Núria Ferran-Ferrer
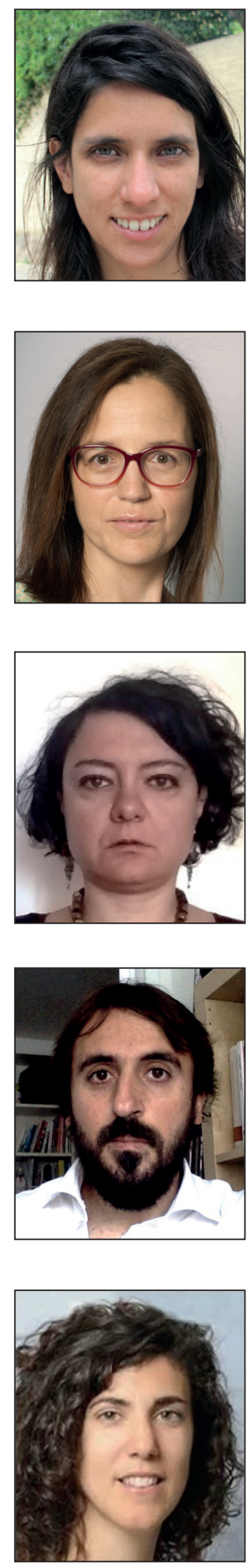

Andrea Rosales, PhD, is a postdoctoral researcher at IN3-UOC. Since 2014 she has combined ethnographic explorations and tracked data analysis, with an intergenerational perspective. She highlights the importance of critical analysis of smartwatch logs and experiences in understanding how to design smartwatch apps that take older people's interests into account.

http://orcid.org/0000-0001-8506-5126

Universitat Oberta de Catalunya Av. Carl Friedrich Gauss, 5. 08860 Castelldefels (Barcelona), Spain arosalescl@uoc.edu

Mireia Fernández-Ardèvol, PhD, is a researcher at the IN3-UOC. Since 2003 she has studied the influence of mobile communications in our societies from a socioeconomic perspective. In this area, she is particularly interested in the intersection of aging and digital communication from a non-patronizing, non-ageist perspective.

http://orcid.org/0000-0002-6938-1943

Universitat Oberta de Catalunya Av. Carl Friedrich Gauss, 5. 08860 Castelldefels (Barcelona), Spain mfernandezar@uoc.edu

Francesca Comunello, $\mathrm{PhD}$, is an associate professor in the Department of Humanities, Lumsa University, Rome (Italy). Her research and publications focus on the intersections between digital technology and society, including network theories, digitally-mediated social relations, social media, social network sites, mobile communication, digital communication and natural disasters, and digital inequalities.

http://orcid.org/0000-0001-5845-5807

Lumsa University Borgo Sant'Angelo 13, 00193 Roma, Italy f.comunello@lumsa.it

Simone Mulargia, PhD, has been a postdoctoral research fellow in the Department of Communication and Social Research (Coris), Sapienza University of Rome, since 2010. He teaches new media, online journalism, and sociology of communication. His research and publications study the relationship between culture, technology, and society, focusing on the role of digital media. http://orcid.org/0000-0002-6131-3479

Sapienza University of Rome Via Salaria 113, 00198 Roma, Italy simone.mulargia@uniroma1.it

Núria Ferran-Ferrer, PhD, has been associate professor at the Faculty of Information and Communication Sciences at the Universitat Oberta de Catalunya (UOC) (Barcelona, Spain) since 2005. She teaches qualitative research methodologies and user experience design, and she researches user behaviors, needs, and motivations.

http://orcid.org/0000-0002-9037-8837
Universitat Oberta de Catalunya Av. Tibidabo, 39-43, 08035 Barcelona, Spain nferranf@uoc.edu 


\begin{abstract}
While wearable technologies, such as smartwatches, are seen as an opportunity to solve some problems often related to older people (65+), e.g. emergencies, physical activity, or isolation, little is known about how older people would domesticate such new technologies. In this study we provided eleven older individuals with smartwatches and tracked their expectations and initial experiences using two interviews. According to our preliminary findings, previous experience with ICTs along with optimistic attitudes toward technology were key to initial domestication of the new technology and overcoming initial problems. Moreover, use was closely related to expectations and personal habits. Participants in this study used smartwatches in similar ways to to those described in previous studies with adults (18-64), including managing notifications and sports' tracking. Additionally, users reported that the smartwatch provided a boost in social status (associated with attributes such as cool, snobbish, young) and created some fashion opportunities and/or concerns.
\end{abstract}

\title{
Keywords
}

Expectations; Domestication; Appropriation; Smartwatches; Wearables; Older people.

\section{Resumen}

Las tecnologías wearables, como los smartwatches (relojes inteligentes), se han visto como una oportunidad para resolver problemas, a menudo relacionados con las personas mayores (55+), tales como manejo de emergencias, falta de actividad física, y soledad. Sin embargo poco se sabe sobre en qué medida tales personas apropiarían estos dispositivos. Dotamos a 11 personas mayores con relojes inteligentes y seguimos sus primeras experiencia principalmente con dos entrevistas. De acuerdo con los resultados, las experiencias previas con otras tecnologías de la información y la comunicación, y las actitudes positivas hacia la tecnología fueron fundamentales para una primera apropiación de la nueva tecnología, y para superar los primeros problemas. Además el uso estuvo muy relacionado con las expectativas y los hábitos personales. Los participantes usaron los relojes en forma similar a la descrita en estudios previos con adultos (18-64), que incluye el manejo de notificaciones y los sistemas para seguimiento deportivo. El reloj proveía a la mayoría de los participantes un status social (asociado a ser guay, snob o joven), y creaba oportunidades o preocupaciones sobre el estilo personal.

\section{Palabras clave}

Expectativas; Domesticación; Apropiación; Smartwatches; Relojes inteligentes; Wearable; Personas mayores.

Rosales, Andrea; Fernández-Ardèvol, Mireia; Comunello, Francesca; Mulargia, Simone; Ferran-Ferrer, Núria (2017). “Older people and smartwatches, initial experiences". El profesional de la información, v. 26, n. 3, pp. 457-463.

https://doi.org/10.3145/epi.2017.may.12

\section{Introduction}

In the 1990s wearables were envisioned as an opportunity to access personal information on the go, thus acting as "visual memory prosthetic(s) and perception enhancer(s)" (Mann, 1997) capable of changing cultural concepts of everyday life (Martin, 2002). Probably due to the recent irruption of smartwatches into the market, there are too few studies on smartwatch use to validate this hypothesis (Lyons, 2015; Schirra; Bentley, 2015; Cecchinato; Cox; Bird, 2015; Pizza et al., 2016; Ashbrook et al., 2008; Giang et al., 2015).

Despite the increasing demographic and social importance of older people in Europe and other developed countries (Melorose; Perroy; Careas, 2015), and the fact that older people are often behind in the appropriation of new technologies, which is leading to a digital divide, none of these studies included older people or made an intergenerational analysis. Nonetheless, wearable technologies are seen as an opportunity to solve problems related to older people, such as, managing emergencies, controlling health indicators, encouraging physical activity, or fighting isolation (Ehrler; Lovis, 2014; Casilari; Oviedo-Jiménez, 2015), and few smartwatch apps give accounts of these trends (Ehrler; Lovis, 2014 for homecare; e.g. Casilari; Oviedo-Jiménez, 2015 for fall detection). This perspective, while interesting, tends to reproduce a patronizing viewpoint in which older people are seen as dependent, disempowered individuals.

We present an analysis of the initial domestication of this particular wearable technology, the smartwatch, among a group of older individuals (65 to 80 ). We look at how individuals integrated the watch into their daily activities, which allows a nuanced understanding of communication practices. As with other age cohorts in previous studies, participants mirrored their expectations and already existing everyday life habits into their use of the smartwatch. Results challenge the idea that digital devices should only be approached as tools for overcoming the limitations associated with aging.

\section{Theoretical framework}

We mainly rely on the domestication approach (Silverstone et al., 1992; Loos; Haddon; Mante-Meijer, 2012). A framework to analyze qualitative data, which proposes that the meaning of technologies, and the related usage practices, emerge during different stages: (1) appropriation, during which time users negotiate the meaning of a device, which can lead, or not, to its acquisition; (2) incorporation, during which time the technology takes its place in users' homes; (3) objectification, when users consider the location of the technology in everyday routines; and (4) conversion, focu- 
sing on the role of the technology in user's self-presentation practices and identity performances.

The design of this research project, which included providing the smartwatch to (new) users, calls for a different categorization of participants and for a partial redefinition of the domestication approach. Participants in this study are neither classic early adopters (Rogers, 1995), nor forced early adopters (Zhou, 2008). They freely chose to join the experiment, knowing that we were going to provide them with a smartwatch, but as we learned in the interviews, they had no previous interest in purchasing a smartwatch. Nevertheless, the domestication approach helps in highlighting that the very meaning of a new device is a process of negotiation involving both technological features and people's symbolic and social understanding of those features; smartwatches are more than merely machines - they are also cultural objects (Silverstone; Haddon, 1996; Du-Gay et al., 2013).

\section{Research questions}

Our contribution to existing research is the application of the domestication approach to smartwatches, particularly for older people. We believe that such an approach can strongly contribute to shedding light on human aspects related to ICT usage. In this regard, expectations, initial usage practices, and the related meanings play a central role.

Therefore, we propose the following research questions:

RQ1: What is the relationship between participants' (expressed) expectations and their initial usage practices?

RQ2: What are the participants' initial patterns of usage and negotiation of the smartwatch in terms of practices, sensegiving processes, learning strategies, and identity performances?

Wearable technologies are seen as an opportunity to solve problems often related to older people $(65+)$

\section{Methods}

To answer the proposed research questions, with a deep view of the domestication process, we adopted a qualitative approach. The study was developed in Barcelona and Rome with an intercultural perspective. It involves eleven participants: seven in Barcelona (three women, four men), four in Rome (one woman, three man). Participants were between the ages of 65 and 80 , the average age at the beginning of the study was 71.1 years old (standard deviation 5.2). We included the experiences of two participants, who withdrew from the study in Barcelona shortly after starting the project, in addition, we also included reports from one participant's wife, who was closely involved with the experience of using the smartwatch because the couple shared the use of the smartphone associated with the smartwatch.

We provided a Moto $G 360$ smartwatch that participants themselves selected. They had to have a compatible android smartphone. Enrolled participants needed to already be active users of smartphones, demonstrate strong engagement to follow the study, and not have a smartwatch. Participants received monetary compensations for their time in interviews. This study was part of a one-year project, still under development as we write this paper, and participants will be able to keep their smartwatches at the end of the one year project. For the purpose of this paper we will refer to participants with $\mathrm{W}$ for women and $\mathrm{M}$ for men, followed by their age, and in the case of quotations, we will indicate the number of the interview preceded with an "i", i.e. W65_i2.

We provided eleven older individuals with smartwatches and tracked their experiences using interviews, and some training sessions

We collected data by means of semi-structured interviews, training sessions, and complementary support. First, we conducted two interviews. The first interview was conducted before delivering the smartwatches. Conversations focused on the use of communication tools in everyday life, particularly digital media, and the expectations around smartwatches. The second interview, two months after the distribution of the smartwatches, focused on the initial use of the smartwatch, the social experience, habits, and learning strategies developed in relation to it; the interview also focused on both the problems or difficulties and the positive aspects of the new device. Second, during the delivery of the smartwatch we conducted some initial training to help the users to manage their new device, and we provided technical support if it was required by participants.

Authors read and re-read the transcribed interviews to conduct thematic analysis (Braun; Clarke, 2006) and identify common topics and particular cases. The comments received from participants during the recruitment process and training sessions and personal support were also taken into account.

\section{Results and discussion}

Participants' domestication processes are related to multiple factors, including individual as well as social and relational dimensions, contextual elements, and previous experiences with ICTs.

The domestication processes we observed during the research occurred in an intervened setting. First of all, due to the design of the study, participants did not experience a traditional "appropriation" stage. They did make a relevant decision on whether to take part, or not, in the study. Participants had to take into account considerations about the watch itself, their previous relationship with technologies, and their own interest in being the subject of a study.

In this sense, few individuals invited to participate in the study rejected the invitation, arguing no interest in the smartwatch, or in devoting time to explore a new technology. In addition, two participants quit the project shortly after the beginning of the study. They argued that the effort-benefit relationship was not positively balanced, or they had privacy and security concerns. This is in line with the fact that 
lack of interest toward ICTs is often the most common reason for not using ICTs (Helsper; Reisdorf, 2016).

Otherwise, for some of the participants, being part of a research project constituted relevant motivation for both adopting the watch and for using it on a constant basis, maybe with an attitude toward exploring specific features that were different from what we might expect, etc.

Second, because smartwatches were not used widely in Barcelona or Rome when the study began, participants were only able to experiment with weak social interactions using their smartwatches. While some of the members of their relational networks engaged in conversations about the watch, no participant seemed to have met someone wearing a smartwatch outside the project. The lack of a suitable user base in participants' relational networks implies that social representations and social usage norms, that generally play a relevant role in shaping user appropriation of a new device, are only partially involved in the processes we observed. Consequently, we witnessed a peculiar appropriation and sense-giving process, which seems to rely more on individual characteristics than on shared meanings and practices; appropriate usage practices (which are typically related to social norms) also undergo peculiar negotiation patterns.

Regarding expectations (RQ1), even though participants did not have a clear idea of the features of smartwatches, most of them generally expected to replace the smartphone with the smartwatch, or to use it for the same activities as their smartphones. Some commented that it could become an essential device in the same way as other technologies that have changed their life. For now, I say 'No! [I don't need a smartwatch]'. But, maybe, in the future, I might say to you: 'Don't take it away from me!'” (W65a_i1) ${ }^{1}$. Yet, after two months of use, appropriation and usage practices appear strongly related to initial expectations, and to the metaphors adopted for understanding the smartwatch.

\section{Previous experience with ICTs along with optimistic attitudes toward technology were key to initial domestication of the new technology}

Moreover, intrinsic interest in technologies was key for joining the project and it was more relevant than the smartwatch itself. For most participants exploring a new technology is a challenge they like to take on and part of the motivation to participate in the study:

"I like having things because I don't want to lag behind." (M76a_i1)

"I moved to Chile during the 1970s for about five years. During this time, I used to write letters, and I made one phone call. After that, the phone became more popular, then the computer came along, the mobile phone, and email. With each new technology you have to explore it, until you discover how it can be useful for you." (W80_i1)

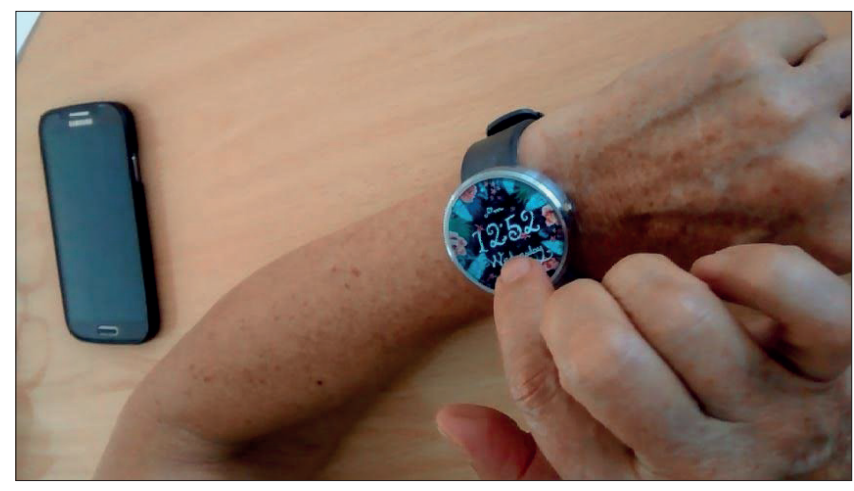

Study participant using her smartwatch

In this, we could establish some parallelism with young individuals who like "geeking out" (Ito et al., 2010) in the digital world. Together with the older people participating in this project, they share a common curiosity for using new technologies, even though motivations for such curiosity might differ.

Participants reflected in their initial smartwatch use, their expectations and existing habits of everyday life. In particular, no one began a new sports practice once they started wearing the smartwatch or started to use a new app using the new wearable as a pretext.

Regarding initial usage and negotiation of the smartwatch (RQ2), some participants seemed to be oriented toward a passive usage, sometimes explicitly using the word "passive" while describing their approach to the smartwatch and with major attention to its usage as a conventional wristwatch during our conversations. For most participants its use is not different from the use described in previous studies about smartwatch use by adults, where the wearable is mostly used for sports tracking and notifications (Cecchinato; Cox; Bird, 2015; Schirra; Bentley, 2015; Pizza et al., 2016), evidence of which also appeared in our study. Interestingly, participants showed a different approach toward notifications, ranging from simply receiving them on the smartwatch and then reacting on the smartphone, to a deeper integration that relied on the smartwatch when the smartphone was not available or its use would have been inappropriate.

Routines of use appeared early as participants tried to wear the device as regularly as possible-the first step in eventually viewing the smartwatch as an ordinary object (Gronow; Warde, 2001). While some of the participants explicitly refer to their commitment to the research project as a motivation for constant usage, it is worth underlining that we never required them to use it constantly and, on the contrary, we suggested that they used it as if it was their own. One participant reported: "[I use it] always, always. It took the place of my watch... Well, if you decide to do this experiment, you have to do it." (M65 i2). The permanent use could be related to the previous usage of a conventional wristwatch, which is now replaced by the digital wearable, but not all participants had a conventional wristwatch. In addition, the practice of recharging is similar to what any smartphone owner is used to. 
Smartwatches have been seen as an opportunity to develop apps for health monitoring and a study demonstrated their usefulness in this area (Jovanov, 2015). However, participants did not expect to use it for health monitoring. For heart monitoring, particularly, they relied on their own specialized devices and used the smartwatch as a proxy. Moreover, no participant saw it as an alternative for solving problems often related to older people in $\mathrm{HCl}$ (e.g. managing emergencies, controlling health indicators, encouraging physical activity, or fighting isolation). Interestingly, the discourse of older individuals is far from the literature discourse, a relevant observation when it comes to creating interest for an IT product for this target population.

Regarding sense-giving processes, and similar to previous studies, two months after beginning to use the smartwatch, older participants were still in the process of creating meaning for their smartwatch. Two facts support this finding: first, some of the participants expected the smartwatch to do the same things as their smartphone (Schirra; Bentley, 2015; Pizza et al., 2016); second, the mobile phone, the computer, and the watch were all metaphors they used for approaching the smartwatch (and often, they confused the words "smartphone" and "smartwatch").

Older people made similar use of the smartwatches to that described in previous studies with adults (18-64)

Learning strategies, which are particular for older people in ICT (Sayago; Forbes; Blat, 2013), were twofold. On the one hand, most participants relied on their previous experience with computers, making it evident that their is importance in prior knowledge when managing new learning situations, which is often a major issue for older individuals who have never been in direct contact with ICT.

"As I did with the mobile phone. Touching, typing, looking, browsing, and then, little by little, I got through it. It's not hard, in terms of the settings. At the beginning it seemed hard. For example, that thing for the heart [heart monitoring App], but then I saw that it works." (W65_i2)

On the other hand, despite regular use, some participants remained at a very basic level of understanding of the system, and they exerted little effort to overcome this situation. This situation might have change, or not with further experience, use, or number of social interactions with the smartwatch.

The smartwatch itself was used to reinforce identity, the simple ownership of the object provided social status that included being cool, young, or snobbish. And this was a motivation for our participants to use the smartwatch. Most users in Barcelona associated the smartwatch with their young and digital identities, most of them boasted about it, and it was relevant for being up-to-date. After the training session, a participant said "Now I will take a picture with my smartwatch and will send it to my friends." (W75)

In contrast, participants in Rome, despite reporting that they used it (almost) every day, seemed to disdain the snobbish connotation of the new technology. Similar to other adult users in other studies, most participants had aesthetic concerns related to the smartwatches (Cecchinato; Cox; Bird, 2015; Lyons, 2015; Schirra; Bentley, 2015). Participants did not find it appropriate to wear a smartwatch in elegant situations. Some even lamented the need to stop using their previous "luxury" watches (in Rome) or other nice watches (Rome and Barcelona). This highlights how fashion appeal is an important dimension regarding adoption. Despite these nuances we identified no cultural differences between the experiences in Rome and Barcelona. In fact, differences were mainly due to personal interests, values, and social contexts.

The results of the study challenge information research about new information/communication technologies and older people. First, the study shows the complexity of the initial process of the domestication of new technologies, especially those technologies that are not yet widespread and require technical skills, previous experience with technology, personal interest, social support, ideologies, and values, are all factors that need to be taken into account. Second, the study shows the complexity of expecting to change habits/behaviors with new technologies or the difficulty of expecting to engage non-users with new habits (Selwyn, 2006). While previous studies have argued that the physical constraints of the watches (small screen, low power battery) are significant barriers to the adoption of these tools (Ehrler; Lovis, 2014) those were not limitations for the participants of the study when using smartwatches on a regular basis during the first two months of the study. Moreover, usage practices seemed to be related to the metaphors users adopted to understand new devices, and to the meanings they attached to them.

The smartwatch provided a boost in social status (associated with attributes such as cool, snobbish, young)

\section{Conclusions}

Eleven individuals, from ages 65 to 80 , participated in this study. We provided them with a smartwatch in order to explore the appropriation process during the initial period of adoption of this new device.

Results show that an intrinsic interest in technologies was key in participants' initial acceptance of the new technology, being more relevant than the features themselves. Participants used the smartwatch in different ways or for different purposes, although the most common was to manage notifications or to keep track of sports activities. Otherwise, for some participants, initial usage was also related with an interest in boasting about it and as a way to keep up-to-date technologically. Moreover, participants' use of the smartwatch reflected their expectations and the already existing habits of their everyday life. However, no participant saw it as an alternative for solving the problems often related to older people (e.g. managing emergencies, controlling health indicators, encouraging physical activity or fighting isola- 
tion). And after two months of usage, some participants still expected to replace the smartphone with the smartwatch and/or are are still grappling with a basic understanding of how their smartwatch operates.

This paper discusses and brings to light new evidence of the expectations and initial appropriation of smartwatches among older individuals. However, two months of use only provided information about the initial stages in the appropriation process. To strengthen the results, a one-year study of participants could help in following up and adding to the understanding of the process of appropriation, or domestication. In addition, an intergenerational comparison would be of interest to better understand the use of older individuals from a non-ageist point-of-view because results are caused merely by age, but instead by life experiences and conditions of research design. Ageism, the complex and often negative construction of old age, has been described as a key contributor to the second digital divide (Lagacé et al., 2015).

Finally, it would be of high interest to develop a quantitative analysis of smartwatch logs to better understand their discours (Ørmen; Thorhauge, 2015), particularly regarding usage and sense-giving processes.

\section{Acknowledgement}

The authors are indebted to all participants who took part in the studies and acknowledge the support from the Ageing + Communication + Technology project (ref. 895-2013-1018, Social Sciences and Humanities Research Council of Cana$d a)$, which partially funded this project.

http://actproject.ca

\section{Note}

1. Authors' own translation from either Catalan, Spanish, or Italian.

\section{References}

Ashbrook, Daniel; Clawson, James; Lyons, Kent; Patel, Nirmal; Starner, Thad (2008). "Quickdraw: The impact of mobility and on-body placement on device access time". En: Proceedings of the SIGCHI Int/ conf on human factors in computing systems. CHI'08, pp. 219-222.

https://goo.gl/pvezPc

https://doi.org/10.1145/1357054.1357092

Braun, Virginia; Clarke, Victoria (2006). "Using thematic analysis in psychology". Qualitative research in psychology, v. 3, n. 2, pp. 77-101.

http://eprints.uwe.ac.uk/11735/2/thematic_analysis_ revised_final.pdf

https://doi.org/10.1191/1478088706qp063oa

Casilari, Eduardo; Oviedo-Jiménez, Miguel A. (2015). “Automatic fall detection system based on the combined use of a smartphone and a smartwatch". Plos one, v. 10, n. 11, pp. 1-11. https://doi.org/10.1371/journal.pone.0140929

Cecchinato, Marta E.; Cox, Anna; Bird, Jon (2015). "Smartwatches: the good, the bad and the ugly?". En: Proceedings of the $33^{\text {rd }}$ Annual ACM conf. Extended abstracts on human factors in computing systems, CHI'15, pp. 2133-2138.

http://discovery.ucl.ac.uk/1462135

https://doi.org/10.1145/2702613.2732837

Du-Gay, Paul; Hall, Stuart; Janes, Linda; Madsen, Anders K.; Mackay, Hugh; Negus, Keith (2013). Doing cultural studies the story of the Sony walkman. Sage. ISBN: 9782849205504

Ehrler, Frederic; Lovis, Christian (2014). "Supporting elderly homecare with smartwatches: Advantages and drawbacks". Studies in health technology and informatics, v. 205, pp. 667-671.

https://doi.org/10.3233/978-1-61499-432-9-667

Giang, Wayne C. W.; Shanti, Inas; Chen, Huei-Yen W.; Zhou, Alex; Donmez, Birsen (2015). "Smartwatches vs. smartphones: A preliminary report of driver behavior and perceived risk while responding to notifications". In: Procs of the International conf on automotive user interfaces and interactive vehicular applications, pp. 154-161.

https://goo.gl/XITZcE

https://doi.org/10.1145/2799250.2799282

Gronow, Jukka; Warde, Alan (eds.) (2001). Ordinary consumption. London, New York: Routledge. ISBN: 9780203381502

Helsper, Ellen J.; Reisdorf, Bianca C. (2016). "The emergence of a 'digital underclass' in Great Britain and Sweden: Changing reasons for digital exclusion". New media \& society, pp. 1-18.

https://doi.org/10.1177/1461444816634676

Ito, Mizuko; Baumer, Sonja; Bittanti, Matteo; Boyd, Danah; Cody, Rachel; Herr-Stephenson, Becky; Horst, Heather A.; Lange, Patricia G.; Mahendran, Dilan; Martínez, Katynka Z.; Pascoe, C. J.; Perkel, Dan; Robinson, Laura; Sims, Christo; Tripp, Lisa; Antin, Judd; Finn, Megan; Law, Arthur; Manion, Anne; Mitnick, Sarai; Schlossberg, David; Yardi, Sarita (2010). Hanging out, messing around, and geeking out: Kids living and learning with new media. Cambridge, MA: The MIT Press. ISBN: 9780262013369

Jovanov, Emil (2015). "Preliminary analysis of the use of smartwatches for longitudinal health monitoring". Procs of the Annual intl conf of the IEEE Engineering in Medicine and Biology Society - EMBS, pp. 865-868.

https://doi.org/10.1109/EMBC.2015.7318499

Lagacé, Martine; Charmarkeh, Houssein; Laplante, Joelle; Tanguay, Annick (2015). "How ageism contributes to the second-level digital divide: The case of Canadian seniors". Journal of technologies and human usability, v. 11, n. 4, pp. 1-13.

http://jthu.cgpublisher.com/product/pub.296/prod.25 https://goo.gl/dEyAv3

Loos, Eugène; Haddon, Leslie; Mante-Meijer, Enid (eds.) (2012). Generational use of new media. Farnham, UK: Ashgate. ISBN: 9781409426578

Lyons, Kent (2015). "What can a dumb watch teach a smartwatch?". Procs of the ACM Intl symposium on wearable computers - ISWC'15, pp. 3-10.

https://doi.org/10.1145/2802083.2802084 
Mann, Steve (1997). "Wearable computing: A first step toward personal imaging". Computer, v. 30, n. 2, pp. $25-$ 32.

\section{https://doi.org/10.1109/2.566147}

Martin, Thomas L. (2002). "Time and time again: Parallels in the development of the watch and the wearable computer". Procs of the Intl symposium on wearable computers, ISWC'02, pp. 5-11.

https://doi.org/10.1109/ISWC.2002.1167212

Melorose, Jeffrey; Perroy, Ryan; Careas, Sylvana (2015). World population prospects, United Nations.

https://doi.org/10.1017/CB09781107415324.004

Ørmen, Jacob; Thorhauge, Anne-Mette (2015). "Smartphone log data in a qualitative perspective". Mobile media \& communication, v. 3, n. 3, pp. 335-350.

https://doi.org/10.1177/2050157914565845

Pizza, Stefania; Brown, Barry; McMillan, Donald; Lampinen, Airi (2016). "Smartwatch in vivo". Procs of the 2016 $\mathrm{CHI}$ Conf on human factors in computing systems. ACM, pp. 5456-5469.

https://doi.org/10.1145/2858036.2858522

Rogers, Everett M. (1995). Diffusion of innovations. New York: Free Press. ISBN: 0029266505

https://teddykw2.files.wordpress.com/2012/07/everett-mrogers-diffusion-of-innovations.pdf

Sayago, Sergio; Forbes, Paula; Blat, Josep (2013). “Older people becoming successful ICT learners over time: Challenges and strategies through an ethnographical lens". Educa- tional gerontology, v. 39, n. 7, pp. 527-544. https://doi.org/10.1080/03601277.2012.703583

Schirra, Steven; Bentley, Frank R. (2015). “It's kind of like an extra screen for my phone: Understanding everyday uses of smart watches". Procs of the $33^{\text {rd }}$ Annual ACM conf extended abstracts on human factors in computing systems. ACM, pp. 2151-2156.

https://doi.org/10.1145/2702613.2732931

Selwyn, Neil (2006). "Digital division or digital decision? A study of non-users and low-users of computers". Poetics, v. 34, n. 4-5, pp. 273-292.

https://doi.org/10.1016/j.poetic.2006.05.003

Silverstone, Roger; Haddon, Leslie (1996). "Design and the domestication of ICTs: Technical change and everyday life". In: Silverstone, R. and Mansell R. (eds.) Communication by design. The politics of information and communication technologies, pp. 44-74. ISBN: 9780198294009

Silverstone, Roger; Hirsch, Eric; Morley, David (1992). "Information and communication technologies and the moral economy of the household". In: Silverstone, Roger; Hirsch, Eric (eds.). Consuming technologies, media and information in domestic spaces. Routledge, p. 256.

https://doi.org/10.4324/9780203401491

Zhou, Yuqiong (2008). "Voluntary adopters versus forced adopters: Integrating the diffusion of innovation theory and the technology acceptance model to study intra-organizational adoption". New media \& society, v. 10, n. 3, pp. 475-496. https://doi.org/10.1177\%2F1461444807085382

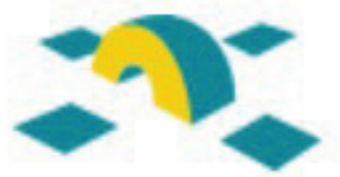
ॠIRIS

\section{https://www.rediris.es/list/info/comunicacion.htm/}

Comunicación es una lista de distribución en castellano para debatir y estar al día sobre teoría de la comunicación, comunicación política, comunicación industrial, relaciones públicas, comunicación audiovisual y multimedia, radio y televisión, cinematografía, periodismo, periodismo de datos, divulgación de la ciencia, medios y cibermedios, redes sociales... y todos los aspectos relacionados con la COMUNICACIÓN.

Empezó a funcionar en enero de 2017 y está alojada en el servicio de listas de RedIRIS, desde donde es posible consultar sus archivos:

https://listserv.rediris.es/cgi-bin/wa?AO=COMUNICACION

La lista cuenta con 2 moderadores que permanentemente filtran los mensajes para evitar spam, mensajes inapropiados, anuncios, mensajes repetidos, etc.:

$$
\begin{aligned}
& \text { Isabel Olea (EPI, León) } \\
& \text { Tomàs Baiget (EPI, Barcelona) }
\end{aligned}
$$

Puedes suscribirte a Comunicación en:

https://listserv.rediris.es/cgi-bin/wa?SUBED1=COMUNICACION\&A=1 